Revista Monografias Ambientais

Santa Maria, Edição Especial Curso de Especialização em Educação

Ambiental. 2015, p. 01-07

Revista do Centro de Ciências Naturais e Exatas - UFSM

ISSN : 22361308

\title{
A Influência Cultural na Prática da Educação Ambiental em Duas Escolas Estaduais do Amazonas
}

The Cultural Influence on the Practice of the Environmental Education in Two Schools of the State of Amazonas

\author{
Rafaela Gonçalves de Lemos ${ }^{1}$, Cibele Rosa Gracioli ${ }^{2}$ \\ ${ }^{1}$ Especialista em Educação Ambiental, Aluna do Polo Presencial UAB Panambi, RS, Brasil , \\ e-mail ana_servsocial@hotmail.com \\ ${ }^{2}$ Engenheira Floresta e Doutora em Engenharia Floresta, UFSM, Santa Maria, RS, Brasil \\ e-mail cibelegracioli@gmail.com
}

\begin{abstract}
Resumo
A Amazônia é uma região dotada de importância estratégica em esfera global por seu imenso potencial natural e cultural, havendo uma grande preocupação por parte de todos em conserva-la. Nesse contexto, esse trabalho tem como propósito conhecer a dinâmica cultural dos educandos que se evidencia no contexto socioambiental, ou seja, como a cultura delineia a forma como o homem se relaciona com a natureza e como isso pode servir de base para a abordagem da Educação Ambiental no contexto escolar. O objetivo do trabalho foi identificar a influência da cultura na relação homem - natureza e na percepção socioambiental dos alunos de duas escolas públicas no Amazonas. Aplicaram-se questionários aos alunos da Escola A, situado em uma comunidade ribeirinha, e aos alunos da Escola B, situada na capital, Manaus. Observou-se que os alunos de ambas as escolas expressaram uma percepção socioambiental que sofre uma forte influência das culturas. A partir dessa constatação, conclui-se que a reconfiguração da relação homem - natureza se constitui um grande desafio para os educadores, e saber adequar essas relações à prática da Educação Ambiental torna-se um importante potencial na busca pela sustentabilidade do planeta.
\end{abstract}

Palavras Chaves: Crise Ambiental. Cultura. Relação Homem - Natureza. Sustentabilidade.

\begin{abstract}
The Amazon is a region with strategic importance in the global sphere by its immense natural and cultural potential, and there was concern on the part of all canned it. In this context, this work is to know the cultural dynamics of the students which is evident in the environmental context, ie how culture outlines how man relates to nature and how this can be the basis for the environmental education approach in the school context. The objective was to identify the influence of culture on the relationship man - nature and environmental perception of students from two public schools in the Amazon. Questionnaires were applied to students of School A, situated in a riverside community, and students of the School B, located in the capital, Manaus. It was observed that students from both schools expressed a perception that environmental is strongly influenced cultures. From this evidence, it is concluded that the reconfiguration of the relationship man - nature constitutes a challenge for educators, and know adapt these relationships the practice of environmental education becomes an important potential in the quest for sustainability of the planet.
\end{abstract}

Keywords: Environmental Crisis. Culture. Man - Nature relationship. Sustainability. 


\section{Introdução}

O caráter global e complexo dos problemas ambientais, trouxe a necessidade de encontrar mecanismos capazes de articular as questões sociais e ambientais de diferentes escalas espaciais e temporais, e de diferentes ordens conceituais, em enfoques compreensivos que expliquem os fenômenos multicausados e heterogêneos que constituem os sistemas ambientais (LEFF, 2001).

Observa-se que o fenômeno da globalização trouxe agravantes ainda maiores que intensificaram casa vez mais o processo de degradação ambiental. A globalização "instala a soberania do consumidor no lugar da soberania dos povos, que em seus processos históricos estabelecem as regras de coesão e solidariedade social e os imaginários coletivos que definem as necessidades e desejos das pessoas dentro de organizações culturais diferenciadas" (LEFF, 2006).

Segundo Leff (2009) a construção da sustentabilidade coloca três desafios fundamentais ao processo de globalização que são: econômica: a) conservar a biodiversidade e os equilíbrios ecológicos do planeta e aumentar seu potencial produtivo; b) reconhecer e legitimar a democracia, a participação social, a diversidade cultural e a política da diferença na tomada de decisões e nos processos de apropriação social da natureza; c) repensar o reconhecimento, o saber, a educação, a capacitação e a informação da cidadania na perspectiva de uma racionalidade ambiental.

Para desvelar as questões que envolvem os agravantes da crise socioambiental e suas implicações na sociedade, sobretudo no contexto escolar é necessário compreender o conceito de cultura e a forma como as relações culturais perpassam o contexto da questão socioambiental, ou seja, a forma como essas relações se estabelecem na sociedade e determinam as causas e os efeitos da crise.

Nesse sentido, essa abordagem se apresenta a partir da ideia de que a cultura enquanto, categoria teórica, nos proporciona dois vieses de análise: a decodificação dos aspectos que caracterizam a relação homem e natureza em diferentes sociedades, questões que explicam as implicações ambientais e sociais da crise ambiental. E o processo de enfrentamento da degradação ambiental sobre a perspectiva de sustentabilidade com a efetiva prática da Educação Ambiental, enfatizando o papel da cultura enquanto mediadora na transformação da relação homem e natureza.

\section{Como bem afirma Leff:}

Ante o crescente e acelerado processo de degradação ambiental, assim como de seus efeitos nos desequilíbrios ecológicos e das bases de sustentabilidade ecológica do planeta, pouco a pouco se vem reconhecendo o papel imprescindível da cultura na sustentabilidade ecológica - das diversas culturas na coevolução da natureza e de seu entrelaçamento com a trama ecológica do planeta (LEFF, 2009, p. 272).

Nesse sentido, entender as diferenças entre as culturas é também compreender a "teia de significado" que cada sociedade apresenta sobre determinados aspectos da realidade, isso significa dizer que a partir da cultura podemos desvelar como cada sociedade concebe o conceito de natureza, visualizando o que representa e a forma como o indivíduo se relaciona com ela.

Leff (2006) afirma que a relação homem/natureza pode ser compreendida como uma relação dinâmica, que depende da articulação histórica dos processos tecnológicos e culturais que especificam as relações sociais de produção de uma formação socioeconômica, bem como a forma particular de desenvolvimento integrado ou de degradação destrutiva de suas forças produtivas.

De acordo com Tozoni-Reis (2004), a relação homem-natureza expressa-se por um conjunto de ideias que indicam que o homem deve-se submeter às "leis naturais", como todos os outros seres vivos, para garantir o equilíbrio harmônico da natureza.

Em se tratando da relação homem-natureza na sociedade capitalista, evidencia-se que o paradigma dominante que orienta a lógica capitalista de produção - visão mecanicista da razão cartesiana ${ }^{1}$ - "busca recolocar as pessoas no centro, como sujeitos da ação, tanto no trabalho quanto em todos os demais setores da vida social" (ZABOT, 2002, p.31). Nesse sentido, o homem, visto como "sujeito" da ação pode, portanto, explorar de forma indiscriminada a natureza em nome do avanço da tecnologia.

Layrargues (2009) afirma que a crise ambiental trouxe novos desafios para as sociedades modernas, exigindo uma alteração no rumo civilizatório, e, na tentativa de escapar da catástrofe ambiental,

\footnotetext{
${ }^{1}$ Dois aspectos da filosofia cartesiana aqui expressos vão marcar a modernidade: $1^{\circ}$ ) o caráter pragmático que o conhecimento adquire - "conhecimentos que sejam muito úteis à vida em vez dessa filosofia especulativa que se ensina nas escolas". Dessa forma, o conhecimento cartesiano vê a natureza como um recurso, ou seja, um meio para se atingir um fim, e $2^{\circ}$ ) o antropocentrismo, isto é, o homem passa a ser visto como o centro do mundo; o sujeito em oposição ao objeto, à natureza. O homem, instrumentalizado pelo método cientifico, pode penetrar os mistérios da natureza e, assim, torna-se "senhor e possuidor da natureza (TONOZI-REIS, 2004).
} 
os sistemas sociais vêm se adaptando à nova realidade. Educação ambiental é educação e, como tal, serve ou para manter ou mudar a realidade, reproduzir ou transformar a sociedade.

Nesse sentido, entende-se que há a necessidade de abordagem teórica e prática da educação ambiental: ao discutir sobre isso assume-se uma postura de crítica de como a educação ambiental vem sendo abordada nas escolas. Nesse sentido, para abordagem prática da educação ambiental consideram-se dois aspectos relevantes às particularidades da Amazônia e os padrões culturais que compõem suas diferentes culturas.

Compreender o espaço amazônico, no contexto em que se configura a crise ambiental requer que não esqueçamos que aqui vivem pessoas que têm uma identidade cultural própria, "tecem suas práticas na relação direta com a natureza, seja com a mata, rios, igarapés e lagos, entrelaçando-os no seu próprio modo de viver, no vocabulário e nos termos que usam para traduzir suas vivências e adaptação aos ecossistemas" (CORRÊA, 2003, p.32). É nesses processos que se visualiza a educação ambiental, como uma abordagem que precisa considerar todas essas relações em um direcionamento que considere ações que tenham como princípio o viés da sustentabilidade.

Para tanto, há necessidade de realização de estudos sobre essas questões, para se compreender os debates na região Amazônica, os quais discutem alternativas sustentáveis para a conservação de seus recursos naturais, uma vez que as evidencias deixadas pela modernização imposta, nos últimos anos, colocam a necessidade de considerarmos a complexa teia de relações sociais, que está subjacente na relação homem - natureza.

Nesse sentido, é preciso debater novas abordagens da educação ambiental a partir de uma reconfiguração das relações homem - natureza, isso implica em mudar a forma como homem tem interagido com a natureza no cenário atual, na dinâmica da cultura capitalista. Por isso, torna-se importante discutir e identificar: de que forma a cultura influencia na prática da educação ambiental nas escolas do Amazonas?

Dessa forma, esse trabalho teve como foco o Estado do Amazonas, evidenciando e contrastando duas escolas inseridas em realidades diferentes, que caracterizam o contexto da capital e do interior do Estado, localizado na zona oeste de Manaus, capital e a outra Escola situada em uma comunidade ribeirinha chamada de Purupuru situada às margens do rio Solimões no Município de Careiro - Castanho/ Amazonas.

\section{Metodologia}

Para identificar a influência da cultura na relação entre o homem e a natureza e a caracterizar a percepção socioambiental dos alunos considera-se a seguinte análise: há uma relação entre o homem e a natureza, a dinâmica dessa relação é mediada pela cultura, assim a percepção socioambiental é resultado desse processo de interação, e assume características fundamentadas a partir de suas experiências com o meio - determinados pelos usos e costumes e a forma como interage no ambiente - determinados pela forma como o indivíduo se relaciona com a natureza - por meio do simbólico, (exemplo das populações tradicionais) ou pela ideia de separação - dominação da natureza, onde esta é vista como um meio para se chegar a um fim, o lucro (sociedade capitalista).

Quanto aos fins, o tipo de investigação escolhido para a realização do trabalho é qualitativa e enquadra-se como exploratória. A pesquisa de campo foi realizada em duas escolas estaduais do Estado do Amazonas, uma situada na zona oeste da capital Manaus, e outra no interior do Estado no município de Careiro - Castanho, na comunidade ribeirinha do Purupuru. Para análise dos dados, a escola ribeirinha será identificada por escola A e escola da zona urbana como escola B. A escolha das escolas obedeceu aos seguintes critérios de seleção: condição geográfica, que retrata um cenário da capital e do interior do Estado, uma vez que o foco da pesquisa é fazer uma análise comparativa sobre a influência da cultura na relação homem e natureza e na percepção socioambiental dos alunos de ambas as escolas. Os sujeitos da pesquisa foram os alunos da $2^{\mathrm{a}}$ Série do Ensino Médio de ambas as escolas lócus da pesquisa. Sendo selecionados 24 alunos da Escola A e 24 alunos da Escola. A investigação foi realizada a partir da aplicação de questionário, com perguntas abertas e fechadas, foi estruturado a partir do objetivo da pesquisa, assim 24 alunos da escola ribeirinha, responderam ao questionário, e 24 alunos da Escola de Manaus. A análise dos dados seguiu a abordagem quanti-qualitativo.

\section{Resultados e Discussão}


Na Figura 1 pode-se ter uma ideia de concepção de natureza dos alunos - ao que já foi discutido anteriormente, a concepção de natureza permeia a relação que se estabelece entre o homem e a própria natureza e direciona essa interação que no nosso ponto de vista é mediado pela Cultura de cada sociedade.

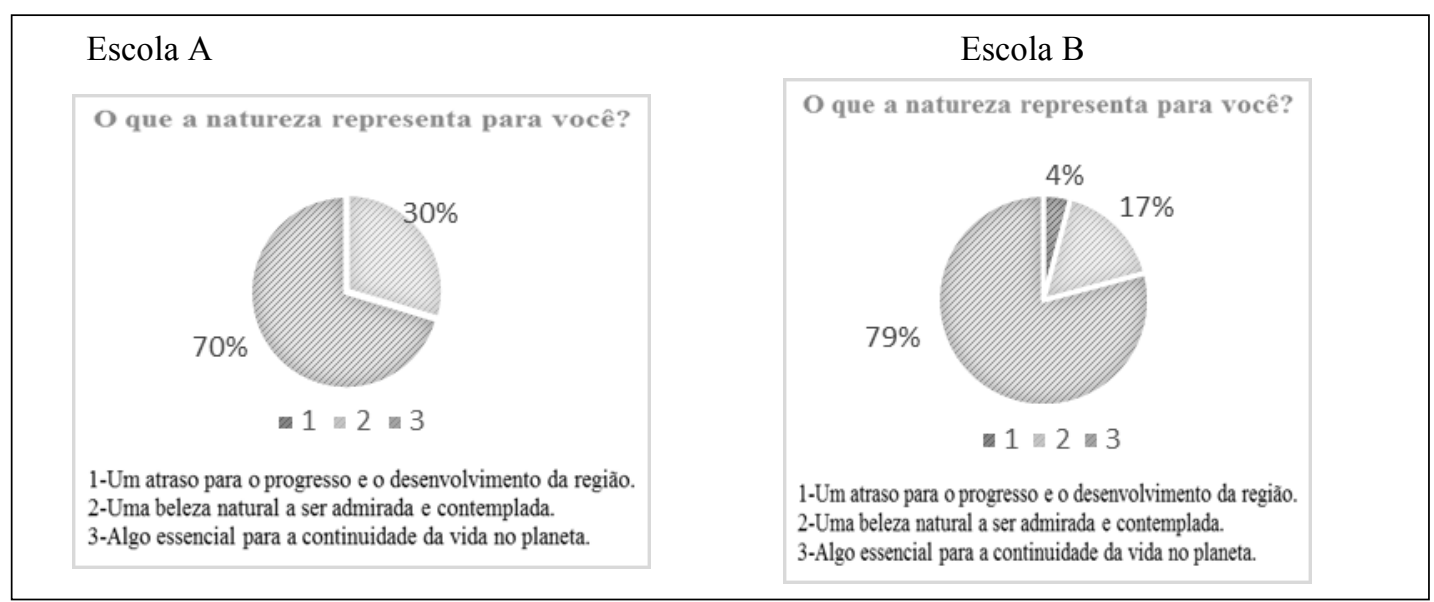

Figura 1- Concepção de Natureza dos alunos, Manaus 2014

Fonte: Elaboração da pesquisadora com base nas informações levantadas na pesquisa de campo, realizada no período de Março a Maio de 2014.

Observa-se que tanto a Escola A quanto os dados da Escola B consideram que a natureza representa "algo essencial para a continuidade da vida no planeta", isso denota que há uma clareza sobre a interdependência que caracteriza a relação homem e natureza. Essa ideia é mais visível aos alunos da Escola A que demonstraram maior interação com a natureza uma vez que $30 \%$ responderam que a natureza representa "uma beleza natural a ser admirada e contemplada" isso se justifica pelo fato de que os aspectos que caracterizam a "cultura ribeirinha" são de interação com a natureza, onde o homem é tido como parte integrante e não como algo a parte, a qual a natureza é subordinada. Por outro lado, dentre os alunos da Escola B alguns 4\% demonstraram se identificar com a concepção de que o homem é o sujeito e por isso é capaz de explorar e submeter a natureza aos seus caprichos, uma vez que consideram a natureza um atraso ao progresso e desenvolvimento da região, características aos fundamentos que caracterizam os princípios da cultura capitalista.

A Figura 2 mostra que ambas as escolas A e B apresentam dados que consideram o homem como parte integrante da natureza, contudo uma variação dos gráficos um com $17 \%$ outro com $8 \%$ consideram que o homem não faz parte da natureza, uma concepção baseada nos fundamentos da visão mecanicista que separa o ambiente em várias partes e que o homem é o sujeito capaz de submeter a natureza a seus próprios interesses.

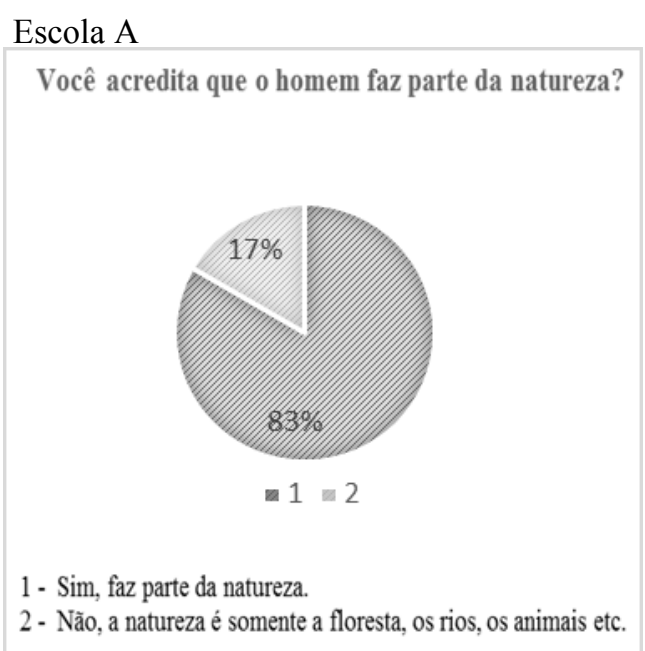

\section{Escola B}

Você acredita que 0 homem faz parte da natureza?

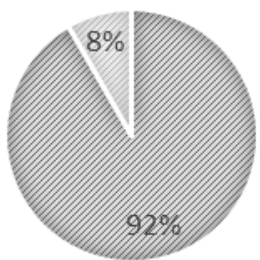

$\because 1=2$

1 - Sim, faz parte da natureza.

2- Não, a natureza é somente a floresta, os rios, os animais etc. 
Percebe-se na Figura 3 que nas escolas A e B há na maioria 63\% e 71\% uma opinião de "negação" de que o homem pode explorar "sem limites" a natureza em nome do desenvolvimento e do progresso da região, contudo há percentual significativo de alunos, $37 \%$ da Escola A que afirmaram o contrário, que o homem pode explorar a natureza sem limites.

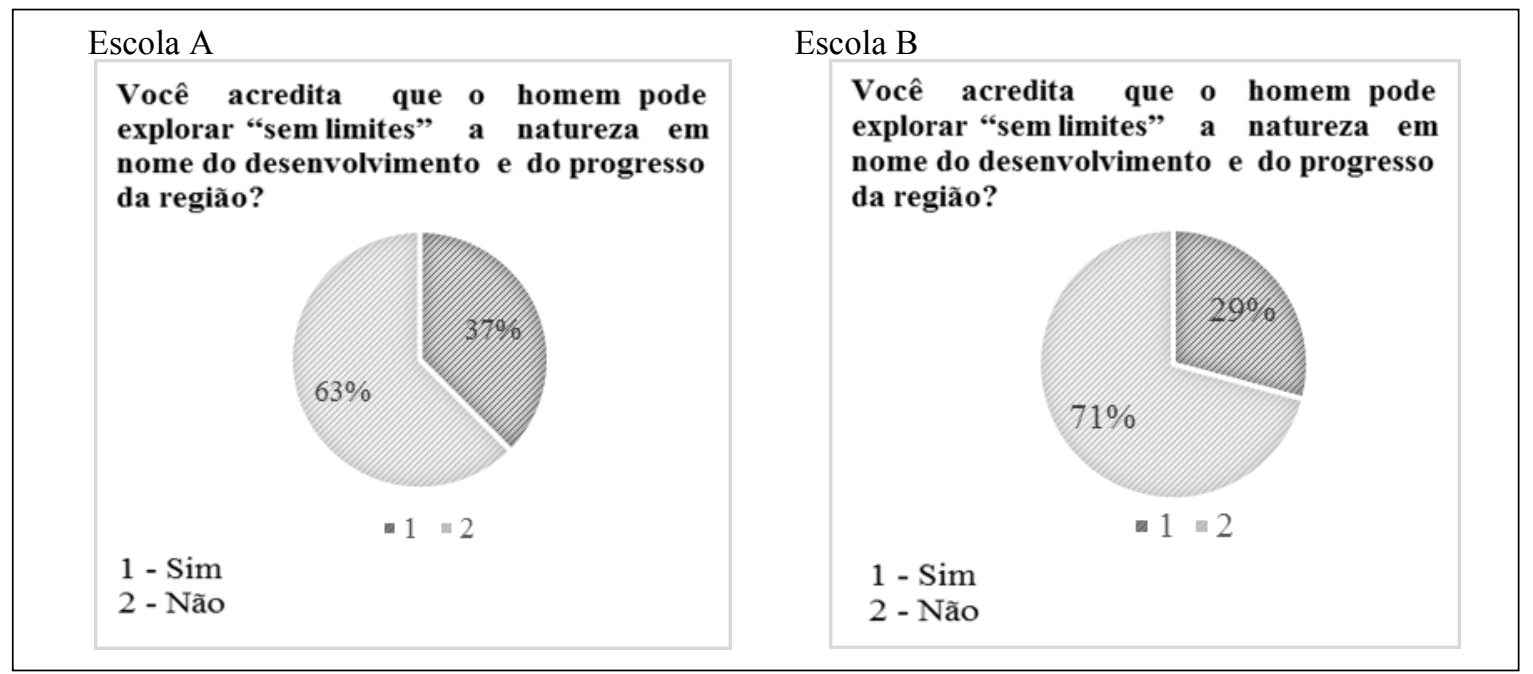

Figura 3 - O contexto que caracteriza o processo de degradação ambiental provocado pelo homem, Manaus, 2014.

Fonte: Elaboração da pesquisadora com base nas informações levantadas na pesquisa de campo, realizada no período de Março a Maio de 2014.

Nota-se que essa consciência ambiental dos alunos sobre a importância de conservar a natureza é vista como imprevisível em uma sociedade que cada vez mais faz apelo ao consumismo disseminado entre jovens e adolescentes por intensa gama de publicidade.

É possível pensar em uma educação ambiental com um viés voltado para ações sustentáveis, superando sua prática isolada do contexto da crise e engendrada a uma ideia de "conscientização" desfocada da realidade, sem considerar o contexto cultural dos educandos (Figura 4).

\begin{tabular}{|c|c|}
\hline Escola A & Escola B \\
\hline $\begin{array}{l}\text { Em sua opinião, quem é o responsável pelo } \\
\text { surgimento dos problemas ambientais? }\end{array}$ & $\begin{array}{l}\text { Em sua opinião, quem é o responsável pelo } \\
\text { surgimento dos problemas ambientais? }\end{array}$ \\
\hline $\begin{array}{l}1-1\|2\| 3 \| 4 \\
1 \text { - O homem } \\
\text { - O crescimento populacional } \\
3 \text { - O consumismo } \\
\text { - A indústria }\end{array}$ & $\begin{array}{l}\qquad 1\|2\| 3 \| 4 \\
1 \text { - O homem } \\
2 \text { - O crescimento populacional } \\
3 \text { - O consumismo } \\
\text { 4- A indústria }\end{array}$ \\
\hline
\end{tabular}

Figura 4 - Possíveis condicionantes que geram a degradação do ambiente apontados pelos alunos, Manaus,2014.

Fonte: Elaboração da pesquisadora com base nas informações levantadas na pesquisa de campo, realizada no período de Março a Maio de 2014.

Os dados na Figura 4 revelam a possibilidade de aliar desenvolvimento com sustentabilidade, $100 \%$ dos alunos consideram essa relação possível, essa constatação implica em uma percepção ambiental que traz aprofundamentos das causas e dos efeitos da degradação, pensar nessa relação é de uma importância significativa considerando que: 
É possível pensar em uma educação ambiental com um viés voltado para ações sustentáveis, superando sua prática isolada do contexto da crise e engendrada a uma ideia de "conscientização" desfocada da realidade, sem considerar o contexto cultural dos educandos.

Dessa forma, a determinação que exerce a dinâmica do capital sobre a transformação dos ecossistemas e a racionalidade do uso dos recursos naturais está sempre condicionada por práticas culturais de aproveitamento dos recursos que medeiam a inter-relação entre os processos ecológicos e os processos históricos. Segundo essa concepção, o processo de humanização dos sujeitos coloca necessidades e capacidades como ser natural incompleto que busca na natureza sua realização objetiva. Se o caráter de uma espécie encontra no tipo de atividade vital que ela exerce, o sujeito concreto é definido pelo trabalho.

Os dados a seguir, da Figura 05 expõem que tanto os alunos da Escola A com 54\% como os da Escola B com $96 \%$ reconhecem que o consumo está relacionado com o processo de degradação ambiental, por outro lado é evidente que uma parte significativa dos alunos da Escola A 46\% desconhecem essa relação, isso demonstra que os alunos não têm clareza suficiente da forma como o sistema capitalista gera a degradação ambiental. Isso porque para atender a demanda da produção e do consumo é necessário retirar matérias primas da natureza, fabricar e transportar materiais, fazer grande uso de energia elétrica e de água, entre outros.

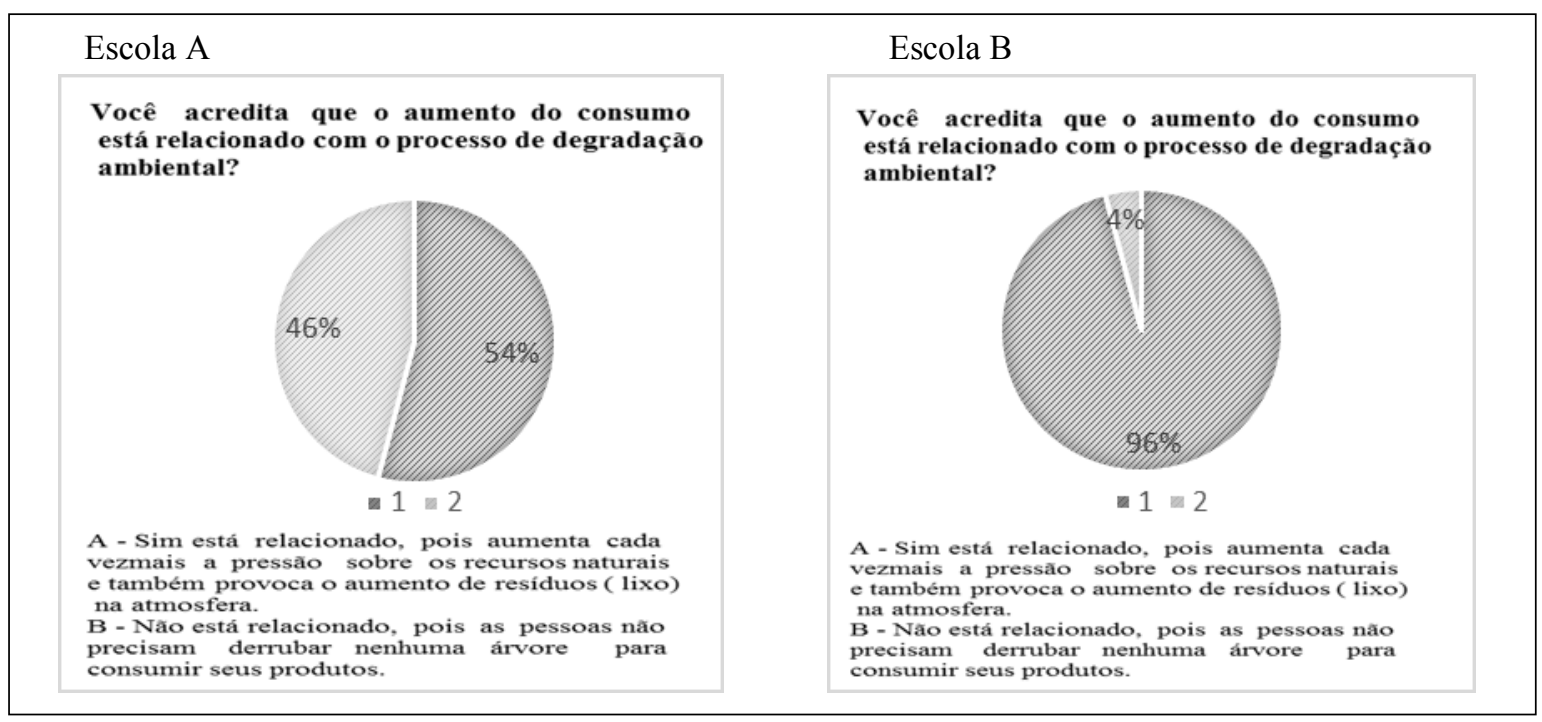

Figura 5 - O consumo exagerado e sua relação com o processo de degradação ambiental, Manaus, 2014

Fonte: Elaboração da pesquisadora com base nas informações levantadas na pesquisa de campo, realizada no período de Março a Maio de 2014

Esses dados mostram que a percepção ambiental da maioria dos alunos (Escola B) é coerente uma vez que é evidente que o consumo exagerado, gera emissão de gases poluentes, degradação e devastação ambiental, poluição geral e, consequentemente, a destruição de ecossistemas. Assim, há uma compreensão dos alunos dos malefícios do consumo exagerado, e de que isso é prejudicial ao ambiente considerando que tem-se um duplo processo de degradação ambiental, que seria o aumento da produção de bens duráveis e não duráveis, já que houve um aumento de consumo e consequentemente isso resultaria numa maior pressão sobre os recursos naturais e também um aumento significativo de resíduos que contaminam a atmosfera, rios, igarapés, gerando um impacto negativo no ambiente.

Por outro lado, os alunos da Escola A demonstraram em uma parcela significativa o desconhecimento dessas questões, isso implica que alguns fatores podem ser elencados para explicar esse quadro, ao que se refere ao pouco comercio (lojas, shoppings, etc) a falta de acesso as tecnologias de informação o que resulta em pouco acesso as campanhas publicitárias de apelo ao consumo, assim chegase a uma conclusão, os alunos da Escola $\mathrm{A}$ dispõe de uma estrutura que não possibilita o consumo exacerbado, isso inclui a falta de recursos financeiros de suas famílias e até mesmo a falta de estrutura do comercio local. Isso tudo descaracteriza os malefícios causados pelo consumismo, uma vez que não é algo visível aos alunos. 


\section{Conclusões}

Na pesquisa observou-se que ampliando as possibilidade de interação entre as diferentes formas de compreensão da relação cultura-natureza, é possível reproduzir essa relação, como sinônimo da própria experiência humana, em contato com a diversidade que ela própria elabora. As relações que se estabelecem dessa dinâmica podem colocar a natureza sob outro ponto de vista uma vez que passa a ter outro significado, o de fazer parte de sua vivência não como um elemento a parte, passivo de destruição, mas como algo que compõe a sua identidade enquanto indivíduo inserido em uma realidade socioambiental.

Partindo dessa constatação, chegam-se as conclusões de que, é possível afirmar que a cultura exerce uma influência significativa na relação homem e natureza, e a percepção ambiental dos alunos é resultado dessas relações sociais que se estabelecem na sociedade e que em se tratando da cultura capitalista provocam os problemas ambientais. Destaca-se que os alunos da Escola A consideram que os problemas ambientais que se apresentam no dia a dia estão relacionados com a natureza e o homem. Percebem que o homem faz parte dessa inter-relação, mais não consideram outras questões como as socioeconômicas introduzidas nesse sistema. Por outro lado os alunos da Escola B demonstraram maior compreensão dos agentes causadores da degradação, contudo na maioria das perguntas não expuseram grandes preocupações com os efeitos devastadores dos problemas ambientais.

Evidencia-se nesse trabalho que a relação entre o homem e natureza é permeada de características vindos da cultura, como prioridade e base para a prática da educação ambiental voltado sobre o viés da sustentabilidade, tendo como princípio o respeito da cultura local e a valorização da participação dos atores sociais envolvidos nesse processo, enquanto responsáveis pela efetivação das ações socioambientais sustentáveis e como forma de conservação da Amazônia.

Nesse sentido, a partir da análise da relação homem - natureza foi possível identificar a percepção ambiental dos alunos e apontar alguns direcionamentos para a prática da Educação Ambiental nas escolas, sobre isso podemos observar:

A percepção ambiental dos alunos se constitui a partir da relação homem - natureza e essa relação é mediada pela cultura, determinando a forma como o homem interpreta e age sobre a natureza, os alunos demonstraram uma certa clareza sobre os agravantes da questão socioambiental e seu impacto na vida das pessoas, isso inclui as interpretações sobre causas e consequências, bem como as ações de enfretamento. A ideia de comparar ambas escolas foi para entender até que ponto a cultura influencia as ações dos alunos tanto no que se refere a concepção de natureza quanto a forma como interage sobre ela, o que permitiu identificar a percepção ambiental dos alunos.

Sobre isso, notou-se que os alunos da Escola A, sob influência direta da cultura ribeirinha, mantém uma maior interação com a natureza, demonstrando maior valorização com os recursos naturais, o que entendemos ser resultado da convivência com a natureza, e dependência dos recursos naturais para sua própria sobrevivência, uma vez que muitos vivem da pesca e da agricultura familiar. Os mesmos demonstraram um conhecimento ingênuo da questão socioambiental o que significa que há pouco aprofundamento das questões que causam a crise ambiental e as saídas para esse problema, contudo notase que os alunos demonstram maior preocupação com o processo de degradação ambiental.

Enquanto que os alunos da Escola B, sobre uma maior influência da cultura capitalista, agregam características que colocam a natureza em segundo plano, a percepção ambiental dos alunos se constitui a partir desses elementos, nota-se que há uma compreensão dos problemas ambiental e dos impactos que eles provocam no ambiente, contudo demonstram pouca preocupação, mas consideram possível o caminho para a sustentabilidade. Observou-se que os alunos têm uma maior compreensão sobre as causas e os efeitos da questão socioambiental, incluindo o consumo exacerbado, contudo muitos alunos não consideram o homem o principal responsável pela degradação o que demonstra a centralidade sobre o homem que permeia a cultura capitalista.

Acredita-se que a educação ambiental se constitui dentro de uma perspectiva crítica/emancipatória, e se efetiva no contexto dos usos, práticas e saberes existentes e vivenciados pelas culturas locais, assim é preciso reconhecer que os aspectos culturais influenciam diretamente na construção de novas posturas éticas em relação as questões socioambientais.

Dessa forma considera-se que é a partir da reconfiguração da relação homem - natureza (toma-se como exemplo a cultura ribeirinha) que é possível se pensar em novas abordagens da educação ambiental na escola, é preciso partir do princípio uma vez que a mudança de postura começa justamente na forma como o indivíduo se relaciona com natureza, para que possa ter consciência da crise ambiental, assumindo um posicionamento crítico e transformador da realidade. 


\section{Referências}

CORRÊA, S. R. M. Comunidades rurais - ribeirinhas: processo de trabalho e múltiplos saberes. In: OLIVEIRA, I. A. Cartografias ribeirinhas: saberes e representações sobre prática sociais cotidianas de alfabetizandos amazônidas. Belém: CCSE-UEPA, 2003.

LAYRARGUES, Philippe Promier. Educação ambiental com compromisso social: o desafio da superação das desigualdades. In LOUREIRO, Carlos Frederico B. (Org.).Repensar a Educação Ambiental: um olhar crítico. São Paulo: Cortez, 2009.

LEFF, Enrique. Ecologia, Capital e Cultura: a territorialização da racionalidade ambiental. (Coleção Educação Ambiental). Petrópolis, RJ: Vozes, 2009.

.Racionalidade ambiental: reapropriação social da natureza. Tradução Luís Carlos Cabral. Rio de Janeiro: civilização brasileira, 2006.

Petrópolis, RJ: Vozes; 2001.

Saber ambiental - sustentabilidade, racionalidade, complexidade e poder.

TOZONI-REIS, Marília Freitas de Campos. Educação ambiental: natureza razão e historia Campinas, SP: Autores associados, 2004.

ZABOT, João Batista M e SILVA, L.C Mello da. Gestão do Conhecimento:

Aprendizagem e Tecnologia, Construindo a Inteligência Coletiva. $1^{a}$.ed. São

Paulo: Atlas, 2002. 